Check for updates

Cite this: RSC Adv., 2017, 7, 46778

Received 15th August 2017

Accepted 12th September 2017

DOI: 10.1039/c7ra09017j

rsc.li/rsc-advances

\section{Cooperative self-healing performance of shape memory polyurethane and Alodine-containing microcapsules}

\author{
Weijie Fan, ${ }^{\text {ab }}$ Weihua Li, (D) *a Yong Zhang, ${ }^{c}$ Wei Wang, (D) ${ }^{a}$ Xiaoying Zhang, ${ }^{a}$ \\ Liying Song ${ }^{a}$ and Xiaojie Liu ${ }^{a}$
}

In this study, a method to prepare self-healing coatings by incorporating Alodine-containing microcapsules as fillers in Shape Memory Polyurethane (SMPU) was presented. Toluene diisocyanate (TDI) prepolymer was prepared for the microcapsule shells, while a healing agent (Alodine 5200) was selected for the core. SMPU with polyethylene glycol (PEG) as the soft segments and isophorone diisocyanate (IPDI) and 2,2hydroxymethyl butyric acid (DMBA) as the hard segments were synthesized as main film-formers. A set of techniques including Fourier transform infrared spectroscopy (FTIR), thermogravimetric analysis (TGA), electrochemical impedance spectroscopy (EIS), Scanning Kelvin Probe (SKP), and optical microscopy were used to completely characterize their self-healing performance on Al 7B04 T74 aluminum alloy surfaces. The study on the self-healing mechanism indicated that the self-healing process can be divided into two stages, and there was enormous potential for repairing large cracks with this technique.

\section{Introduction}

Organic coatings are widely used in metal corrosion protection because of their good properties and simple construction at a reasonable cost. At the same time, cracks in the coatings occur inevitably due to the existence of internal stresses and external damage. ${ }^{1}$ If the cracks are not repaired in time, the coatings soon lose their protective properties. ${ }^{2}$ Self-healing coating, which can be repaired the first time, has attracted the attention of numerous scholars all over the world. Various efforts have been made to develop crack-healing techniques by using new materials or designing new methods. ${ }^{3,4}$

Microcapsules containing fillers such as inhibitors ${ }^{5,6}$ or filmforming reagents ${ }^{7-9}$ were used as self-healing additives in the coating systems. The coating damages could be repaired by the release of core. As described in literature, ${ }^{\mathbf{1 0}, \mathbf{1 1}}$ nano sizes microcapsules were the preferred choice for short term corrosion protection compared to long term. Therefore, a common problem in these systems is the inability to completely reinstall the large defects.

Shape memory polymers (SMP), an emerging class of smart materials, have been employed to prepare new types of selfhealing coatings due to their potential to recover original shapes. ${ }^{12}$ Due to their functional groups, it is possible to create hydrogen bonds between the segments. When the coating is

${ }^{a}$ Institute of Oceanology, Chinese Academy of Sciences, Qingdao 266071, P. R. China E-mail: wjf725@sina.cn

${ }^{b}$ University of Chinese Academy of Sciences, Beijing 100049, P. R. China

${ }^{c}$ Qingdao Branch of Naval Aeronautical University, Qingdao 266041, P. R. China damaged, a physical self-healing is expected after an increase in the temperature between the glass-transition temperature of the hard segment and soft segment. Indeed, with the relaxation of the soft matrix, the polymer can fill the damaged area, while the hard segments maintain the mechanical properties. ${ }^{13}$ The shape memory is a completely physical process, there is no chemical bond breaking and recombination in the shape recovery process, ${ }^{2}$ and full repairs of the coatings' barrier properties remained challenging, due to the absence of filling and bonding. In this case, the corrosion reaction takes place on the metal surface before the shape reversion occurs. Thus, the presence of corrosion products between the metal and the healed coating will lead to a decrease in adhesion.

Combining the microcapsules with shape memory polymers may be a possible solution to the abovementioned problems. In the current study, we present a method to prepare self-healing coatings by incorporating Alodine-containing microcapsules as fillers in SMPU. Alodine conversion coating is widely used to improve the corrosion resistance and adhesion strength of $\mathrm{Al} / \mathrm{P}$ film, ${ }^{\mathbf{1 4}}$ which containing $\mathrm{Ti}$ and $\mathrm{Zr}$ ions can enable the aluminium alloy to have higher corrosion resistance and better adhesion. Once a crack occurs, the structure of the microcapsule breaks down. The encapsulation of the Alodine inside the microcapsule reacts with aluminium alloy or corrosion products at the bottom of the scratch as pre-treatment, and a dense conversion layer is formed on the substrate surface due to passivation. Further heating treatment activates the shape memory effect of SMPU, and two sides of the scratch move gradually towards each other. Finally, the healed coating has 
better corrosion resistance and adhesion strength due to the presence of the conversion layer.

\section{Experimental}

\subsection{Materials}

All chemicals, unless otherwise noted, were purchased from Sigma-Aldrich and used as received. Butanediol (BDO) and dibutyltin dilaurate were purchased from Aladdin. Polyethylene glycol (PEG) with $M_{\mathrm{n}}$ values of 2000 was dried overnight in vacuum $\left(120{ }^{\circ} \mathrm{C} / 5\right.$ mbar $)$ over $\mathrm{P}_{2} \mathrm{O}_{5}$ before being used. $N, N$ dimethylformamide (DMF) was purified by vacuum distillation after being dried with anhydrous magnesium sulfate. Furthermore, Alodine 5200 was purchased from Henkel Company, which is a non-chrome titanium based conversion coating. The non-chrome treatments are designed to replace chromate conversion coatings in applications where they cannot be used for environmental/safety reasons. Aluminum alloys Al 7B04 T74 used in this study were kindly offered by AVIC Xi'an aircraft industry (group) company LTD and their chemical composition is shown in Table 1.

\subsection{Preparation of microcapsules}

Toluene diisocyanate (TDI) prepolymer was prepared for the microcapsule shells, while a healing agent (Alodine 5200) was selected for the core. The synthesis route were carried out by following the previous reports, ${ }^{\mathbf{1 5}}$ as shown in Fig. 1 a.

First, toluene 2,4-diisocyanate (TDI, Sigma-Aldrich, $10 \mathrm{~g}$ ) was dissolved in $5 \mathrm{ml}$ of cyclohexanone in a flask $(250 \mathrm{ml})$. The mixture was kept in different temperature $\left(70{ }^{\circ} \mathrm{C}, 75^{\circ} \mathrm{C}, 80{ }^{\circ} \mathrm{C}\right)$ oil bath and stirred using a mechanical roaster. Dry nitrogen was introduced to the chamber with a low rate of $5.00 \mathrm{ml} \mathrm{min}{ }^{-1}$. Then, 1,4-butanediol (BDO, $2.00 \mathrm{~g}$ ), dibutyltin dilaurate (0.05 g), and dimethylolbutanoic acid (DMBA, $0.50 \mathrm{~g}$ ) were dissolved in the TDI solution under agitation (1500 rpm). The reaction continued for $8 \mathrm{~h}$ before being distilled at $110{ }^{\circ} \mathrm{C}$ under vacuum for $6 \mathrm{~h}$ in order to remove excess materials. After that, Alodine $5200(2.00 \mathrm{ml})$ was poured into the mixture to form an $\mathrm{O} / \mathrm{W}$ emulsion. The oil bath was heated to $75{ }^{\circ} \mathrm{C}$ and butanediol $(0.03 \mathrm{~mol})$ was added as chain extender. After $45 \mathrm{~min}$, the suspension of microcapsules was cooled, repeatedly rinsed with deionized water and dried under vacuum for $24 \mathrm{~h}$. The composition diagram of the Alodine-containing microcapsules is shown in Fig. $1 \mathrm{~b}$.

\subsection{Preparation of shape memory polyurethane}

The SMPU used in this study is constituted of PEG $\left(M_{\mathrm{n}} 2000\right)$ as the soft domains and polyurethane segments (PU) as the hard domains. The synthesis of the SMPU polymer containing 5.5 wt $\%$ of hard segment and coating application were

Table 1 Chemical composition of 7B04 T74 aluminum alloys

$\begin{array}{llllllllllll}\text { Element } & \mathrm{Zn} & \mathrm{Mg} & \mathrm{Cu} & \mathrm{Mn} & \mathrm{Fe} & \mathrm{Si} & \mathrm{Ni} & \mathrm{Cr} & \mathrm{Ti} & \mathrm{Al}\end{array}$ $\begin{array}{lllllllllll}\mathrm{w} / \% & 6.23 & 2.88 & 1.58 & 0.31 & 0.15 & 0.048 & <0.01 & 0.16 & 0.025 & \text { Bal }\end{array}$

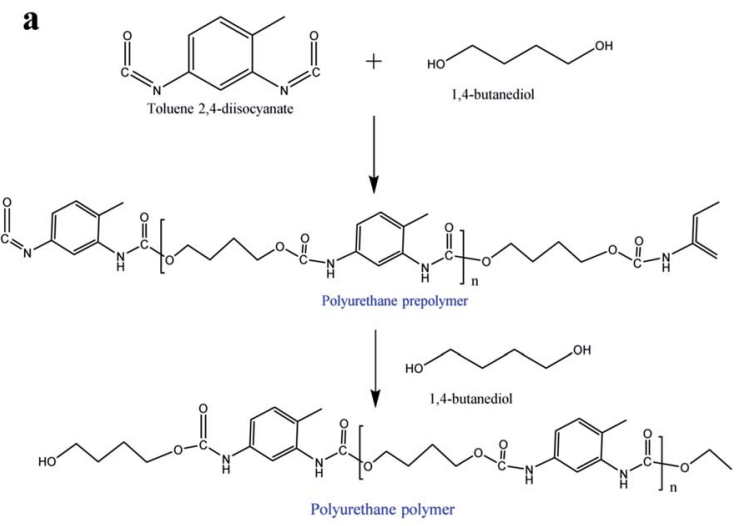

b

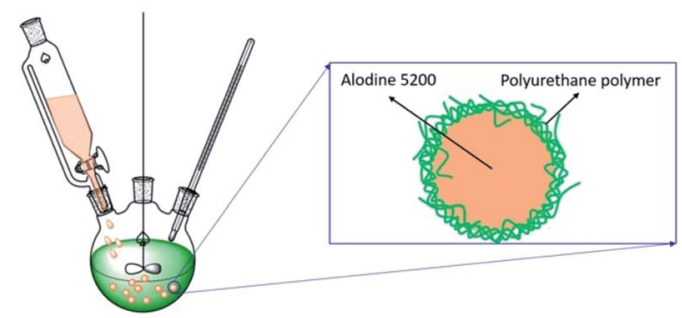

Fig. 1 (a) Schematic of polyurethane polymer, (b) composition diagram of the Alodine-containing microcapsules.

performed as described in ref. 16. The schematic of shape memory polyurethane is shown in Fig. 2.

At room temperature, PEG (20 g), which was dried overnight at $115{ }^{\circ} \mathrm{C}$, dry acetone $(10 \mathrm{ml})$, isophorone diisocyanate (IPDI, $5.3 \mathrm{~g})$, and dibutyltin dilaurate $(0.05 \mathrm{~g})$ were mixed in a fourneck round-bottom flask $(250 \mathrm{ml})$ with nitrogen purging. The mixture was then kept in different temperature $\left(70{ }^{\circ} \mathrm{C}, 75^{\circ} \mathrm{C}\right.$, $80^{\circ} \mathrm{C}$ ) oil bath and stirred using a mechanical roaster for $2 \mathrm{~h}$. Afterwards, hydroxymethyl butyric acid (DMBA, $1 \mathrm{~g}$ ) was dissolved in methyl formamide (DMF, $5 \mathrm{ml}$ ) and slowly added to reaction solution as chain extender. The reaction continued for

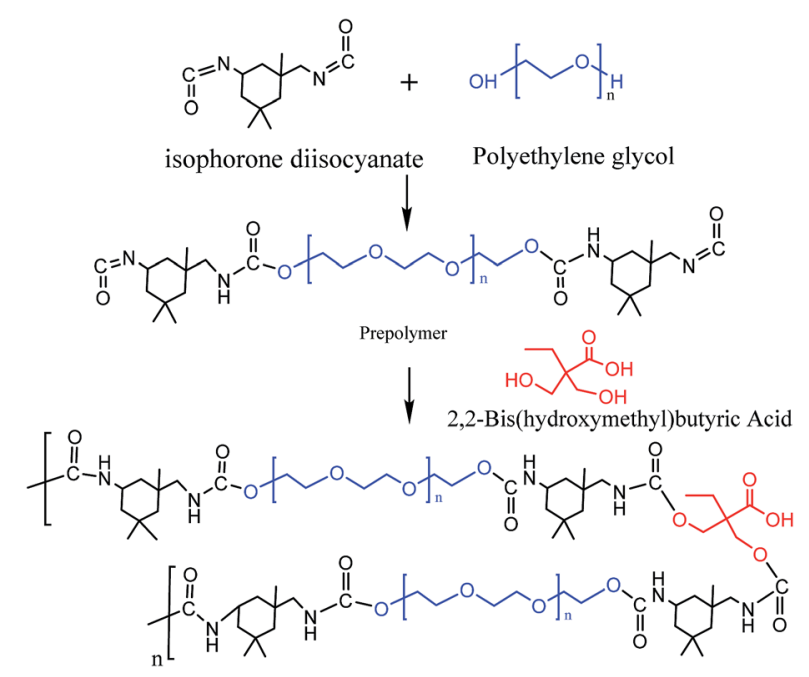

Fig. 2 Schematic of shape memory polyurethane. 
4-5 $\mathrm{h}$ before being cooled to room temperature. The $\mathrm{pH}$ was adjusted to approximately 7.0 using triethylamine. Finally, the SMPU was successfully synthesized and heat-treated at $90{ }^{\circ} \mathrm{C}$ for 1 hour to complete the polymerization reaction.

\subsection{Preparation of the substrates}

Al 7B04 T74 aluminum alloys were used as the substrate and first grounded by 240 grit abrasive paper to remove the surface oxide layer. Prior to all measurements, the aluminum samples $(10 \mathrm{~mm} \times 10 \mathrm{~mm} \times 10 \mathrm{~mm}$ ) were sealed in PVC pipes (outside diameter was $32 \mathrm{~mm}$ and length was $30 \mathrm{~mm}$ ) with epoxy resin and triethylenetetramine (compounding ratio $11: 1$ ). The surface for tests was ground from 400 to 1000 grade SiC paper, rinsed with absolute ethyl alcohol, and finally dried in air.

To prepare the self-healing coatings, microcapsules and shape-memory polyurethane were mixed carefully by mechanical stirring. The sealed samples were coated by bar coating at $65{ }^{\circ} \mathrm{C}$ and cooled to room temperature before they were annealed for $24 \mathrm{~h}$ at $65{ }^{\circ} \mathrm{C}$ in a vacuum oven. The distance between the bar and the substrate was $100 \mathrm{~mm}$.

\subsection{Characterization}

In order to identify the successful synthesis of microcapsules, the morphology was examined using optical stereomicroscopy (Hirox KH-7700) in the final emulsion and mixed with shape memory polyurethane. Thermal stability of the microcapsules was studied using thermogravimetric analysis. Small amounts of microcapsules (1-2 mg) were heated from 25 to $650{ }^{\circ} \mathrm{C}$ at a rate of $10{ }^{\circ} \mathrm{C} \min ^{-1}$ in a $\mathrm{N}_{2}$ environment.

The shape-memory properties of the polyurethanes were investigated according to ref. 17. The specimens (average diameter was $5 \mathrm{~mm}$ and length was $58 \mathrm{~mm}$ ) were first stretched into a length as long as possible at $70{ }^{\circ} \mathrm{C}$, and the shapes could be fixed by cooling the specimens to room temperature rapidly. When the specimens were heated to $70{ }^{\circ} \mathrm{C}$ again, they started to recover to their permanent shape, and during this process the length between two sides was measured at regular intervals. The shape recovery ratio $(R)$ was calculated using eqn (1):

$$
R=\frac{L_{1}-L_{2}}{L_{1}-L_{0}} \times 100 \%
$$

where $L_{0}$ is initial length of the specimens, $L_{1}$ is the fixed longest length and $L_{2}$ is the final recovery length.

Fourier transform infrared spectroscopy (FT-IR) tests were performed using a Perkin Elmer 1600 FTIR to confirm the soft segments and hard segments of synthesized polyurethane, and the spectrum was recorded in $600-4000 \mathrm{~cm}^{-1}$ range.

The self-healing performance of the coatings was evaluated by typical corrosion tests. Scratches were applied manually using a razor blade on the prepared coatings and then the coatings were placed horizontally at room temperature for 3 hours in the first stage. After that, the sample was subsequently heated to $70{ }^{\circ} \mathrm{C}$, kept for the next 2 hours, and allowed to heal itself. The cooperative self-healing performance of the reference group of polyurethane without microcapsules was also investigated. Electrochemical impedance spectroscopy (EIS) was measured to monitor the entire process using a PARSTAT 4000 electrochemical station. The frequency ranged from $10^{5} \mathrm{~Hz}$ to $10^{-2} \mathrm{~Hz}$, a total of 51 points. The entire electrochemical cell was placed in a Faraday cage to avoid interference from external electromagnetic fields and stray currents. Moreover, the surface morphologies of the coatings were observed by optical stereomicroscopy (Hirox KH-7700) during the entire self-healing process. The Scanning Kelvin Probe (SKP) technique was conducted to show the potential difference along the crevice in a measurement chamber, which kept the temperature and humidity stabilized. Corrosion potential maps of typically $2 \mathrm{~mm}$ $\times 2 \mathrm{~mm}$ covering a scratch were obtained with step of $100 \mu \mathrm{m}$ using Uniscan Model 370. The results were presented as $3 \mathrm{D}$ images. It is worth to note that the low resolution was associated with faster acquisition rates to avoid the effects of time. To observe the compatibility of the Alodine coating and recovered polyurethane, the cross-section of the healed scratch was cut and carefully polished without causing further damage to the sample as demonstrated previously. ${ }^{18}$

\section{Results and discussion}

\subsection{Characterization of Alodine-containing microcapsules}

The optical microscopy and particle size distribution of the synthesized Alodine-containing microcapsules in the emulsion are shown in Fig. 3a and b. The capsules had spherical shape, a smooth and non-porous exterior shell wall, and ensured enough space for Alodine and easy dispersion into the coating, which could also be confirmed from Fig. $3 \mathrm{~b}$. The diameter of the microcapsule ranged from $10 \mu \mathrm{m}$ to $80 \mu \mathrm{m}$. Microcapsules with different diameters can be seen to be filled with dark materials,

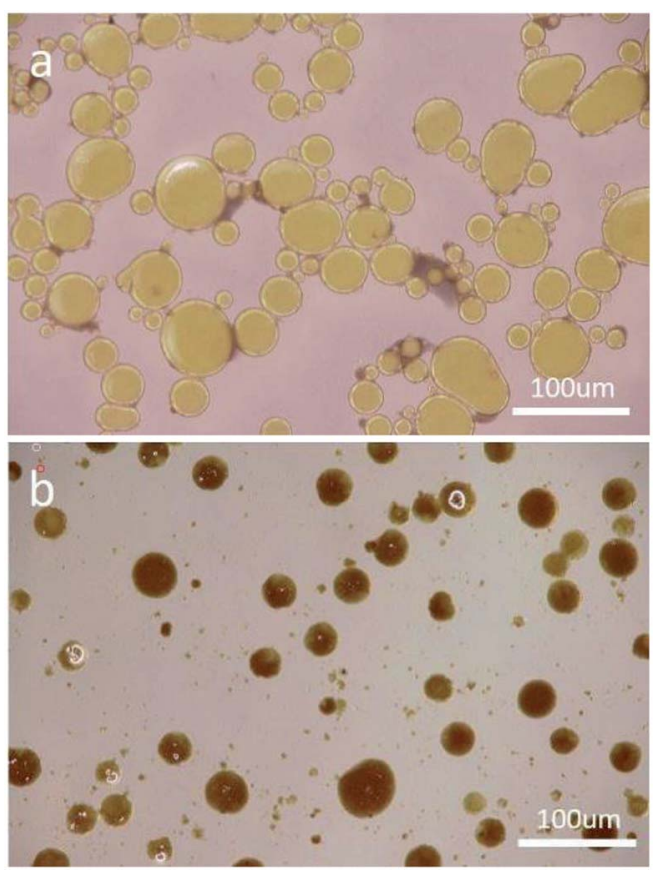

Fig. 3 Optical microscopy images of microcapsules synthesized at $75^{\circ} \mathrm{C}(\mathrm{a})$ in the emulsion obtained after addition of Alodine, and (b) mixed in shape memory polyurethane. 
and the objects were uniformly dispersed in polyurethane, as shown in Fig. 3.

Thermogravimetric analysis (TGA) was applied to identify the thermal properties of filled microcapsules. Effects of different synthesis temperatures $\left(70{ }^{\circ} \mathrm{C}, 75^{\circ} \mathrm{C}, 80^{\circ} \mathrm{C}\right)$ on the stability are depicted in Fig. $4 \mathrm{a}$ and b. The mass loss before $230{ }^{\circ} \mathrm{C}$ correlates to the physical loss of solvent. ${ }^{19}$ Large mass loss peaks at $380-400{ }^{\circ} \mathrm{C}$ (in Fig. 4a) were attributed to the decomposition of Alodine, whereas the final mass loss, which took place in the temperature over $450{ }^{\circ} \mathrm{C}$, is indicative of the decomposition of the shell material, which is consistent with the literature. ${ }^{15}$ The percentage of Alodine in microcapsules was $74.9 \%, 67.6 \%$ and $73.4 \%$ respectively, which was calculated based on TGA analysis and mass loss rates. Therefore, the results demonstrate that there is a steady loading efficiency in different synthesis temperatures (ranging from 70 to $80^{\circ} \mathrm{C}$ ).

\subsection{Characterization of shape memory polyurethane}

The chemical structure of the shape memory polyurethane was characterized by FT-IR. Fig. 5 shows the bending vibration peaks of the $\mathrm{N}-\mathrm{H}$ group at $1537 \mathrm{~cm}^{-1}$ and the stretching vibration peaks of the $\mathrm{C}=\mathrm{O}$ group at $1713 \mathrm{~cm}^{-1},{ }^{20}$ which validate the successful synthesis of the polyurethane. ${ }^{21}$ Maxima peaks found at $1091.57 \mathrm{~cm}^{-1}$ could be assigned as stretching vibration of the $\mathrm{C}-\mathrm{O}-\mathrm{C}$ group. These are usually attributed to the large number of repeating groups of soft segment and its large absorption coefficients. Another favorable evidence is that peaks at $1300 \mathrm{~cm}^{-1}, 1349 \mathrm{~cm}^{-1}$ and $1453 \mathrm{~cm}^{-1}$ ascribed to the bending vibration of $\mathrm{CH}_{2}$ were observed. In addition, the
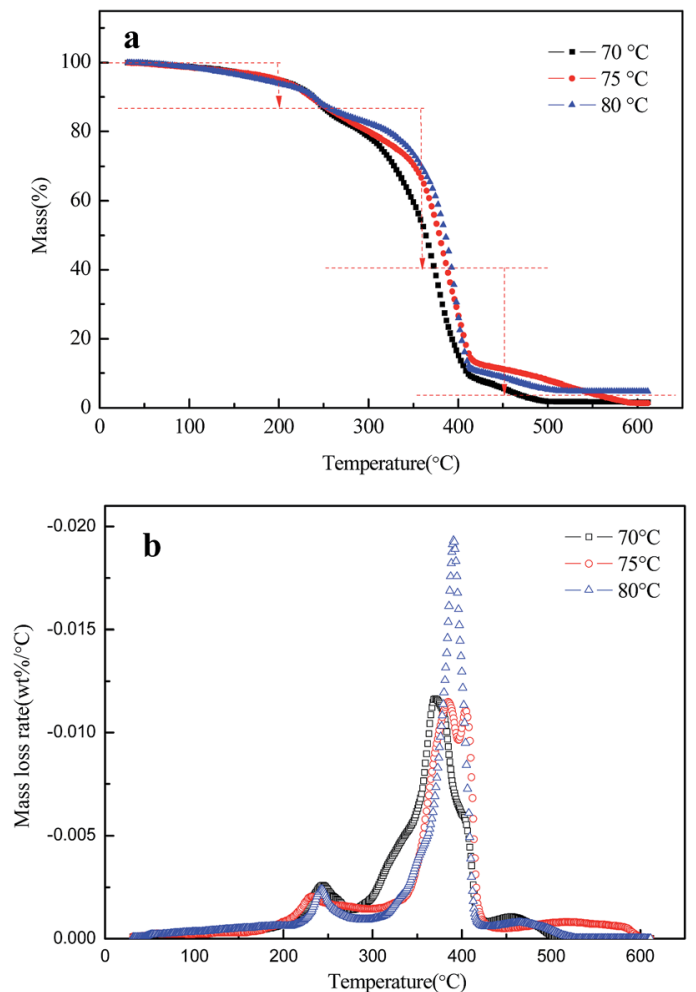

Fig. 4 TGA graphs of microcapsules (a) mass curve, (b) mass loss rate curve.

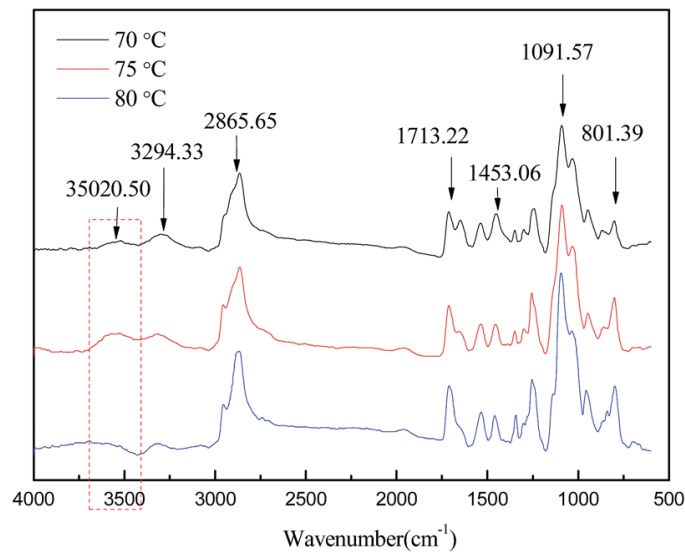

Fig. 5 FT-IR spectral curves of shape memory polyurethane.

stretching vibration peaks of the $\mathrm{CH}_{3}$ group of hard segment could be observed at $2865.65 \mathrm{~cm}^{-1}$. In the spectra obtained at a synthesis temperature of $80{ }^{\circ} \mathrm{C}$, the peaks of $\mathrm{O}-\mathrm{H}$ stretching vibration are red shifted.

The shape-memory behavior of polyurethane was investigated by quantitative measurements. For quantitative investigation (Fig. 6), polyurethane was first stretched into a length as long as possible at a sufficiently high temperature $\left(70{ }^{\circ} \mathrm{C}\right)$ for 1 min with a hair dryer, followed by cooling to room temperature for $5 \mathrm{~min}$. Since the soft segments composed of poly diols undergo glass transition ( $\left.T_{\text {trans }}\right)$ at a relatively lower temperature, it can be deformed by an external force at $70{ }^{\circ} \mathrm{C}$, which is higher than the $T_{\text {trans }}$ of the soft segment and lower than that of hard segment. Accordingly, the shape can be fixed with the temperature decreased below $T_{\text {trans }}$ of soft segment rapidly. Furthermore, the sample was recovered after heating to $70{ }^{\circ} \mathrm{C}$ for about $5 \mathrm{~min}$ due to the movement of soft segment, which indicated the shape memory properties of polyurethane. The shape memory recovery rate was $79.6 \%$, as calculated by eqn (1).

\subsection{Self-healing performance of shape memory polyurethane loaded with microcapsules}

The self-healing process of the coatings was visualized via optical microscopy and divided into two stages. The original

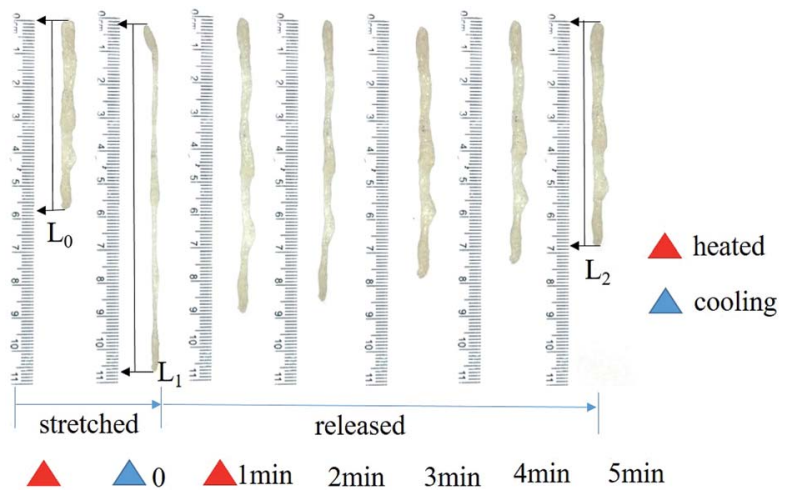

Fig. 6 Shape memory properties of polyurethane ( $L_{0}$ initial length, $L_{1}$ fixed longest length, $L_{2}$ final recovery length). 


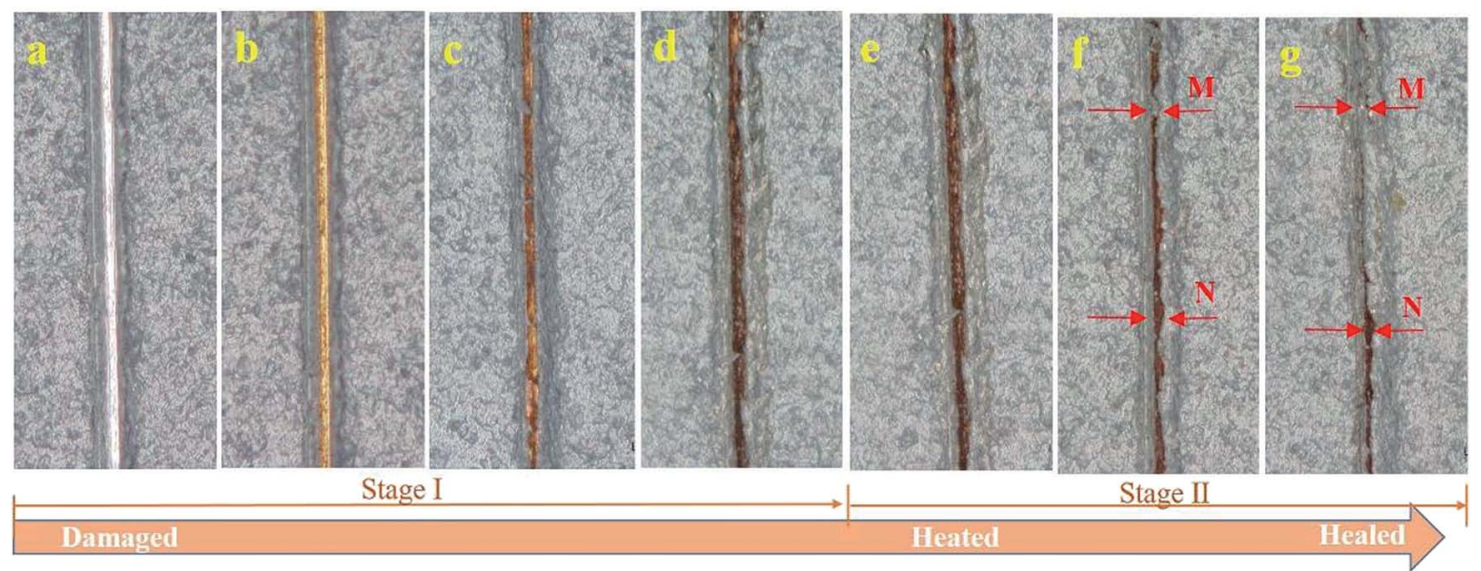

Fig. 7 Optical microscope images of superficially damaged and healed for different time. Scale bar: $2 \mathrm{~mm}$ (a) original defect, (b) defect after $1 \mathrm{~h}$, (c) $2 \mathrm{~h},(\mathrm{~d}) 3 \mathrm{~h}$, and (e) heated to $75^{\circ} \mathrm{C}$ at $4 \mathrm{~h},(\mathrm{f}) 5 \mathrm{~h},(\mathrm{~g}) 6 \mathrm{~h}$.

coating defect was generated by a razor blade, as shown in Fig. 7a, and the shiny surface at the bottom of the scratch indicated that the coating was cut through and the metal substrate was exposed. In the first healing stage without any treatment for $3 \mathrm{~h}$, the shiny substrate became dark gradually, which can be observed by comparing Fig. 7b-d. This accounted for the generation of the novel Ti/Zr conversion coating, which enabled the $\mathrm{Al}$ alloy to have higher corrosion resistance ${ }^{22}$ and better adhesion strength. ${ }^{23}$ After the second healing stage at $75{ }^{\circ} \mathrm{C}$, the shape memory effect of the polyurethane was triggered, recovering the wide scratch to close, as shown in Fig. 7e. On comparing Fig. $7 \mathrm{f}$ and $\mathrm{g}$, we can find that the scratch (point $\mathrm{M}$ ) is almost completely closed, except for some individual positions (point $\mathrm{N}$ ) where even though the crack is not completely closed, the corrosion resistance will be improved ${ }^{10}$ and the adhesion strength of the coatings will be enhanced ${ }^{24}$ due to the existence of the passive film. Fig. 8 showed the cross section of the healed specimen. It is obvious that there is a dark film between the substrate and healed coating at the scratch site, not anywhere else. Thus, it can be inferred that this is the Alodine conversion coating. Moreover, there is no distinct

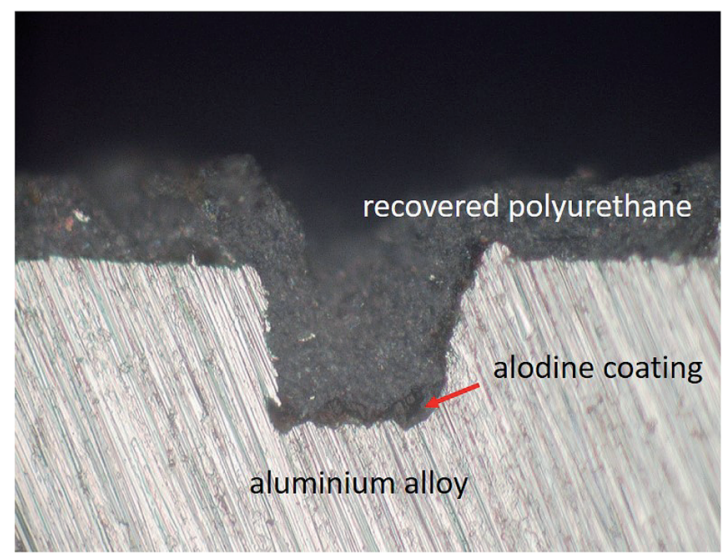

Fig. 8 Optical microscope image of the Alodine coating and recovered polyurethane cross-section. Scale bar: $0.5 \mathrm{~mm}$. interface between the Alodine coating and recovered polyurethane due to good compatibility. This good adhesion facilitates the Alodine coating to polyurethane, and thus improves scratch resistance.

The self-healing process could be described by a two-step "passivated-then-heal" mechanism as shown in Fig. 9. The Alodine-containing microcapsules were evenly dispersed in polyurethane and applied on surface of aluminum alloy (Fig. 9a). In the first step, some of the Alodine mainly containing hexafluorotitanic acid $\left(\mathrm{H}_{2} \mathrm{TiF}_{6}\right)$ and hexafluorozirconic acid $\left(\mathrm{H}_{2} \mathrm{ZrF}_{6}\right)$ was released from the microcapsule cores over time when the coating scratches were formed (Fig. 9b). They reacted with the aluminium alloy to produce Alodine conversion coating that could improve both the adhesion strength and the corrosion resistance of substrate (Fig. 9c). The mechanism of reaction between Alodine 5200 and the aluminum alloy was as follows according to the reports. ${ }^{22,25,26}$ Aluminum dissolves forming $\mathrm{Al}^{3+}$ ions during the initial stages (eqn (2)), and the oxygen reduction in the micro-cathode area produces $\mathrm{OH}^{-}$(eqn (3)).

$$
\begin{gathered}
\mathrm{Al} \rightarrow \mathrm{Al}^{3+}+3 \mathrm{e} \\
\mathrm{O}_{2}+2 \mathrm{H}_{2} \mathrm{O}+4 \mathrm{e} \rightarrow 4 \mathrm{OH}^{-}
\end{gathered}
$$

The above reactions create a local alkalinity adjacent to the intermetallics favouring the precipitation of $\mathrm{TiO}_{2}, \mathrm{ZrO}_{2}$ and $\mathrm{Al}_{2} \mathrm{O}_{3}$ (eqn (4)-(6)).

$$
\begin{gathered}
\mathrm{Ti}^{4+}+4 \mathrm{OH}^{-} \rightarrow \mathrm{TiO}_{2} \cdot 2 \mathrm{H}_{2} \mathrm{O} \\
\mathrm{Zr}^{4+}+4 \mathrm{OH}^{-} \rightarrow \mathrm{ZrO}_{2} \cdot 2 \mathrm{H}_{2} \mathrm{O} \\
\mathrm{Al}^{3+}+6 \mathrm{OH}^{-} \rightarrow \mathrm{Al}_{2} \mathrm{O}_{3} \cdot 3 \mathrm{H}_{2} \mathrm{O}
\end{gathered}
$$

Thus, the main components of conversion coating are $\mathrm{TiO}_{2}$, $\mathrm{ZrO}_{2}$ and $\mathrm{Al}_{2} \mathrm{O}_{3}$.

The second step requires heating at $T>T_{\mathrm{g}}$ of soft segments, which activates the shape memory effect, releasing the restored strained energy in the deformed area and exerting a contracting 

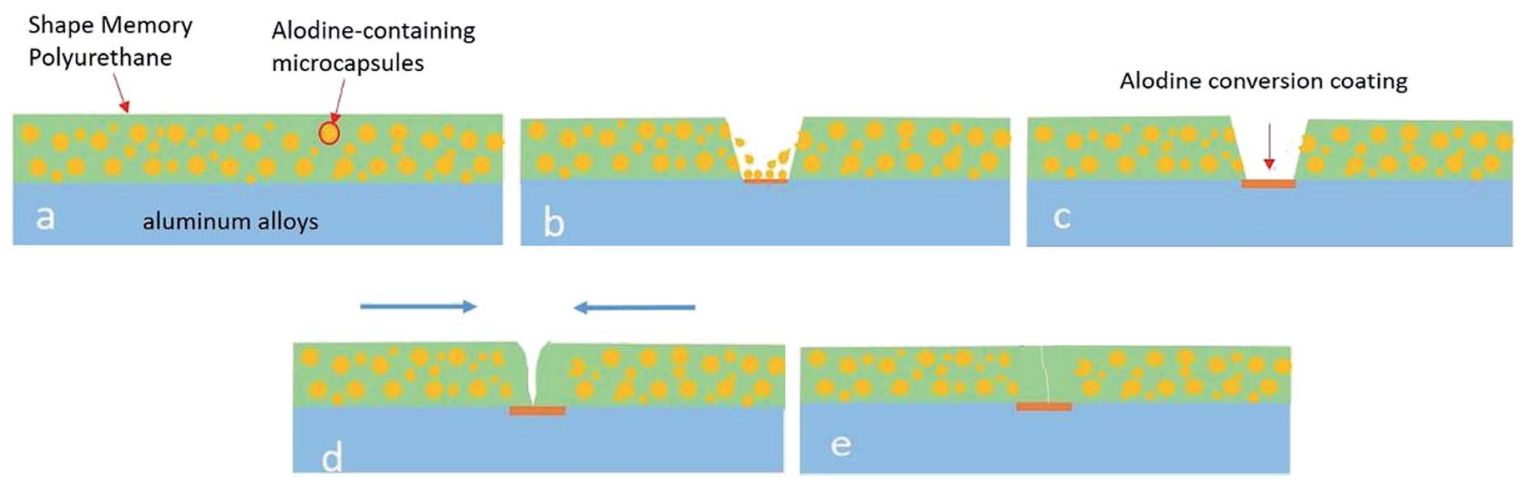

Fig. 9 Schematic of self-healing principle (a) polyurethane loaded with Alodine-containing microcapsules, (b) Alodine were released from the microcapsules when coating defect was damaged, (c) the Alodine conversion coating was formed on aluminum alloy, (d) the shape memory potential of polyurethanes was activated after being heated, (e) the scratch was almost completely closed.

force to close the defect (Fig. 9d). Furthermore, there was an Alodine conversion coating between the healed polyurethane and aluminium alloy (Fig. 9e). The conversion coating has better corrosion resistance than the substrate, while its surface roughness is related to the adhesion strength.

In order to verify the above mechanism, the possibility of Alodine release and the shape memory effect were investigated by the EIS measurements. ${ }^{27}$ Fig. 10a and b show the Nyquist and Bode plots of the EIS spectrum in the first stage of self-healing process for shape memory polyurethane loaded with microcapsules. Once the scratch was formed, the impedance amplitude decreased rapidly. According to literature, ${ }^{28}$ two small capacitive arcs on the Nyquist plot (Fig. 10a, 0 h) imply complete loss of coating properties and that the corrosion of the aluminum alloy occurred at the bottom of the scratch. Then, Alodine, released from microcapsules, reacted with aluminum alloy to form a conversion coating over time, which gradually slowed down the penetration of $\mathrm{Cl}$ ion (Fig. 10a, $0.5 \mathrm{~h}, 1 \mathrm{~h}$ ). Accordingly, the constants in Bode plots (Fig. 10b, $0.5 \mathrm{~h}, 1.0 \mathrm{~h}$ ) disappeared gradually in the low frequency range, which can be attributed to the gradual formation of the passive film. On comparing the capacitive arc at certain times (Fig. 10a), $1.5 \mathrm{~h}$, $2.0 \mathrm{~h}, 2.5 \mathrm{~h}$, we find a rapidly rising trend of radius, which indicates that the passive film is relatively complete over time and the resistance of the substrate is enhanced. ${ }^{29}$ The Bode plots (Fig. 10b) at $1.5 \mathrm{~h}, 2.0 \mathrm{~h}, 2.5 \mathrm{~h}$ show the capacitive response in the low frequency range due to the first stage of self-healing process. ${ }^{30}$ Fig. $10 \mathrm{c}$ and d show the EIS spectrum of coating after heating at second stage, in which the value of the impedance increased rapidly and the second capacitance arc completely disappeared (Fig. 10c). These results clearly confirmed that crack closure by the shape memory effect can, to some extent, enhance the resistance of coatings and reduce the penetration of corrosion..$^{31}$ Eventually, the complete coating (Fig. 10c and d, $24 \mathrm{~h}$ ) exhibits a strong barrier effect by showing one large capacitive arc (Fig. 10c); on the corresponding Bode plot, this is shown as a pure capacitive behavior.

By comparing Fig. 10a and e, two capacitive arcs on the Nyquist plot (Fig. 10e, 0-3 h) can be observed until polyurethane is heated, which implies the corrosion of the aluminum alloy.
The second capacitive arc suddenly disappears with the start of heating. The rising trend of phase angle curves in the middle frequency range (Fig. 10f, 3-6 h) indicates that the resistance of the coatings is enhanced by the self-healing process. It can be seen that the capacitive response in the low frequency range is due to the two side walls of the scratched crevice touching each other.

As shown Fig. 10g, impedance modulus $(|Z|)$ at a frequency of $0.01 \mathrm{~Hz}$ of each Bode plot was used to evaluate the corrosion resistance of coatings. The impedance modulus value $f=0.01$ $\mathrm{Hz}$ ) in the curve of samples with microcapsules could be easily distinguished by two stages. The lowest value at $0 \mathrm{~h}$ accounts for the presence of the scratch, which causes the substrate to be exposed in the corrosion solution directly. Then, the value shows an increasing trend due to the formation of the passive film. Consequently, passivation reaction gradually slows down as the film thickness increases over time. At the second stage, shape memory effects made both sides of the scratch move to each other in the heating environment, and the formation of the physical shielding layer resulted in a rapid increase of the impedance modulus. In fact, the impedance moduli are relatively larger than those of the reference group. Furthermore, the impedance modulus curves of samples without microcapsules show different trends. There is no significant change in initial $3 \mathrm{~h}$ due to the absence of microcapsules. After heating, the impedance modulus increases rapidly and is stabilized at a relatively smaller value to the experimental group due to the shape recovery of polyurethanes. Thus, the difference in impedance value illustrates that the introduction of Alodine microcapsules into the polyurethane leads to significant effect on corrosion resistance or in other words, recovered polyurethane needs Alodine conversion coating to hinder the diffusion of $\mathrm{Cl}$ ions to substrate..$^{32,33}$

Three equivalent circuits were used to fit the EIS data of the coating with Alodine-containing microcapsules at different times. The first, shown in Fig. 11a, was used to fit the impedance spectrum before the passivation film was fully formed. Furthermore, the second equivalent circuit (Fig. 11b) was suitable for the complete passivation film $^{34}$ and the third one (Fig. 11c) indicated that the coating was completely repaired. 

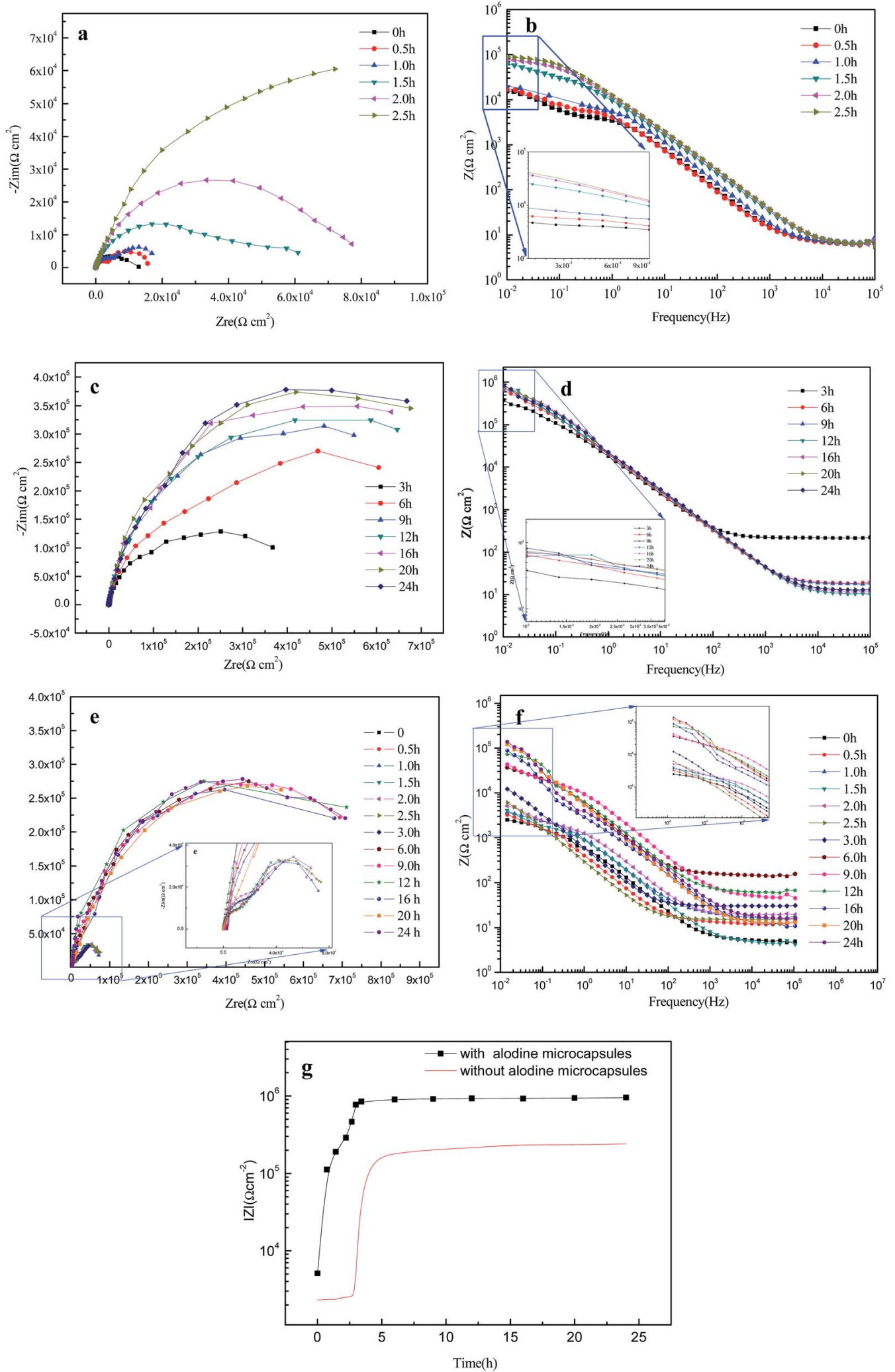

Fig. 10 Electrochemical properties of samples before and after self-healing in $0.3 \mathrm{M} \mathrm{NaCl}$ solution (a) Nyquist spectra and (b) Bode plots in first stage, (c) Nyquist spectra and (d) Bode plots in second stage, (a-d) shape memory polyurethane loaded with microcapsules. (e) Nyquist spectra and (f) Bode plots of shape memory polyurethane without microcapsules and (g) impedance modulus $(|Z|)(f=0.01 \mathrm{~Hz})$ of two different samples during the whole process. 


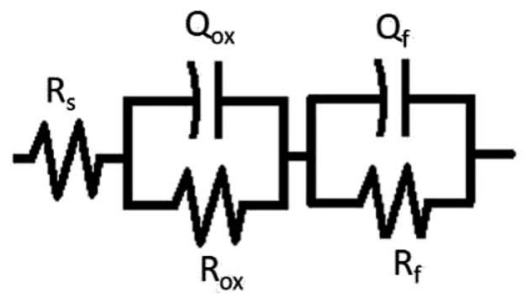

(a)

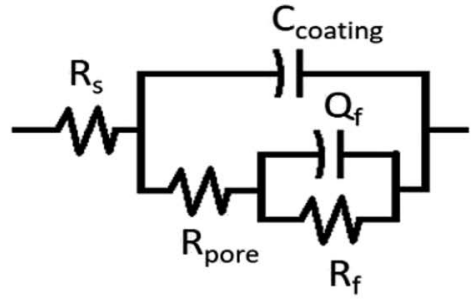

(b)

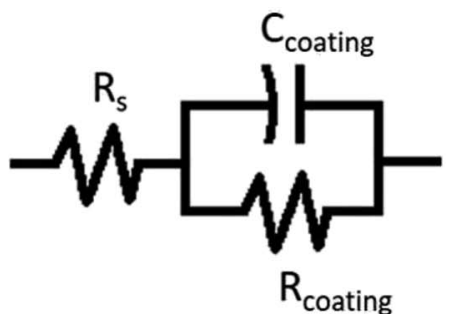

(c)

Fig. 11 Equivalent circuit models used for the data analysis of the coatings, (a) before the passivation film was fully formed, (b) complete passivation film, and (c) the completely repaired coating.

The fitting results of different equivalent circuits are shown in Tables 2-4, where $R_{\mathrm{S}}$ is the resistance of $\mathrm{NaCl}$ solution, $R_{\mathrm{ox}}$ and $Q_{\text {ox }}$ represent the metal charge transfer resistance and double layer capacitance, respectively, ${ }^{35} R_{\mathrm{f}}$ and $Q_{\mathrm{f}}$ represent the resistance and capacitance of passivation film, respectively, $R_{\text {pore }}$ represents pore solution resistance, and $R_{\text {coating }}$ and $C_{\text {coating }}$ represent the coating resistance and capacitance of coating, respectively.

According to the results in Table 2, the increasing trend of the $R_{\mathrm{f}}$ value (from 3.615 to $11.58 \mathrm{k} \Omega \mathrm{cm}^{-2}$ ) indicates that Alodine slowly reacts with aluminum to create the passivation film at the bottom of the scratch within $1 \mathrm{~h}$. After immersion for $2.5 \mathrm{~h}$, the continuous growth (from 41.63 to $64.85 \mathrm{k} \Omega \mathrm{cm}^{-2}$ ) of $R_{\mathrm{f}}$ is related to the gradual integrity of the passive film, as shown in Table 3, and the increasing of pore solution resistance (from 2.271 to $2.973{\mathrm{k} \Omega \mathrm{cm}^{-2}}^{-2}$ due to the size of pores in films getting smaller. However, the values of $Q_{\mathrm{f}}$ gradually decreased (from 9.247 to $7.891 \mu \mathrm{F} \mathrm{cm}^{-2}$ ). The increasing trend of the $R_{\mathrm{c}}$ value (from 282.4 to $723.4 \mathrm{k} \Omega \mathrm{cm}^{-2}$ ) in Table 4 indicates that the coating on the surface of the passivation film has good properties after $24 \mathrm{~h}$. It is evidence that the shape memory properties play an important role in the self-healing process of the coating.

As shown in Fig. 12, the potential maps can be more intuitive to show the entire repair process of the scratched coating. A high and wide peak can be clearly observed in Fig. 12a, which could be explained by the direct exposure of the metal matrix under the scratch. However, this phenomenon changed quickly after a while as shown in Fig. 12b; the peak became weak and the
Table 4 Electrochemical parameters at the second stage of selfhealing process

\begin{tabular}{llll}
\hline Time $(\mathrm{h})$ & $R_{\mathrm{S}}\left(\Omega \mathrm{cm}^{-2}\right)$ & $\left.C_{\text {coating }}(\mu \mathrm{F} \mathrm{cm})^{-2}\right)$ & $R_{\text {coating }}\left(\mathrm{k} \Omega \mathrm{cm}^{-2}\right)$ \\
\hline 3 & 2.280 & 7.405 & 282.8 \\
6 & 2.032 & 5.741 & 503.4 \\
9 & 1.937 & 5.508 & 576.1 \\
12 & 2.136 & 5.128 & 642.6 \\
16 & 2.272 & 5.048 & 711.8 \\
20 & 2.443 & 5.012 & 714.9 \\
24 & 2.224 & 4.902 & 723.4 \\
\hline
\end{tabular}

potential difference with the surroundings decreased due to Alodine releasing from the microcapsule over time, and it reacted with aluminium alloy to produce the passive film at the bottom of the scratch. The formation of the passive film hindered the diffusion of corrosion products in aluminum alloy, and to some extent, it blocked the penetration of the corrosive $\mathrm{Cl}$ ions. Moreover, the dense film was conducive to the adhesion power of the coating. ${ }^{36} \mathrm{Fig} .12 \mathrm{c}$ shows that the peak of potential differences became much smaller after $2 \mathrm{~h}$. Starting from $3^{\text {rd }}$ hour, the width of peak apparently decreased with the progression in heating time, indicating that two sides of the scratch gradually moved towards each other, as shown in Fig. 12d-e. It was evident that the scratch was covered with more and more self-healing polyurethanes. Finally, there was no potential peak left in Fig. 12f indicating that the coating was completely repaired using a combination of the two technologies.

Table 2 Electrochemical parameters in the pre-self-healing

\begin{tabular}{llllc}
\hline Time $(\mathrm{h})$ & $R_{\mathrm{s}}\left(\Omega \mathrm{cm}^{-2}\right)$ & $Q_{\text {ox }}\left(\mu \mathrm{F} \mathrm{cm}^{-2}\right)$ & $R_{\text {ox }}\left(\mathrm{k} \Omega \mathrm{cm}^{-2}\right)$ & $Q_{\mathrm{f}}\left(\mu \mathrm{F} \mathrm{cm}{ }^{-2}\right)$ \\
\hline 0 & 7.463 & 12.96 & 4.677 & 11.64 \\
0.5 & 7.453 & 17.71 & 4.912 & 17.27 \\
1.0 & 7.516 & 19.22 & 4.861 & 19.40
\end{tabular}

Table 3 Electrochemical parameters at the first stage of self-healing process

\begin{tabular}{|c|c|c|c|c|c|}
\hline Time (h) & $R_{\mathrm{S}}\left(\Omega \mathrm{cm}^{-2}\right)$ & $C_{\text {coating }}\left(\mu \mathrm{F} \mathrm{cm}^{-2}\right)$ & $R_{\text {pore }}\left(\mathrm{k} \Omega \mathrm{cm}^{-2}\right)$ & $Q_{\mathrm{f}}\left(\mu \mathrm{F} \mathrm{cm}^{-2}\right)$ & $R_{\mathrm{f}}\left(\mathrm{k} \Omega \mathrm{cm}^{-2}\right)$ \\
\hline 1.5 & 7.318 & 5.610 & 2.271 & 9.247 & 41.63 \\
\hline 2.0 & 7.124 & 5.054 & 2.728 & 8.239 & 62.74 \\
\hline
\end{tabular}



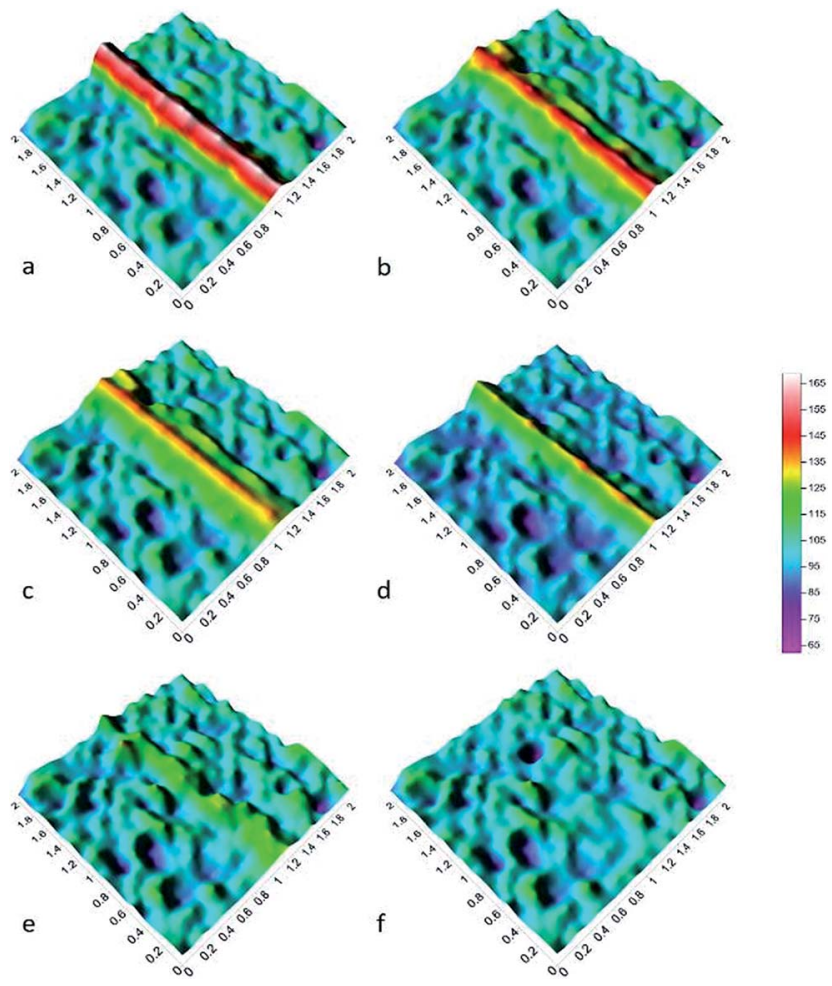

Fig. 12 Potential maps obtained on surface of sample with the Kelvin probe ((a) $0 \mathrm{~h}$, (b) $1 \mathrm{~h}$, (c) $2 \mathrm{~h}$, (d) $3 \mathrm{~h}$, (e) $4 \mathrm{~h}$, (f) $5 \mathrm{~h}$ ).

\section{Conclusion}

The combination of the microcapsules and shape memory polyurethane makes it possible to repair cracks. Alodinecontaining microcapsules were synthesized by interfacial polymerization of polyurethanepre polymer. The results of thermogravimetric analysis demonstrated that there was a steady loading efficiency in different temperatures. The shape memory polyurethane containing polyethylene glycol (PEG) as the soft segments showed excellent recovery rate (79.6\%). Following the results acquired in optical microscopy, EIS and SKP measurements, the entire self-healing process of shape memory polyurethane loaded with Alodine-containing microcapsules was divided into two different self-healing stages. In the first stage, Alodine released from microcapsules enabled the substrate to have higher corrosion resistance and better adhesion strength. After the second healing stage at $75^{\circ} \mathrm{C}$, the shape memory effect could make the wide scratch to close completely.

\section{Conflicts of interest}

There are no conflicts to declare.

\section{Acknowledgements}

The authors would like to gratefully thank the support of the Nantong science and technology plan (grant number GY12016046) and National Natural Science Foundation of China (Grant No. 51401185).

\section{References}

1 M. F. Montemor, Functional and smart coatings for corrosion protection: a review of recent advances, Surf. Coat. Technol., 2014, 258, 17-37.

2 J. B. Jorcin, G. Scheltjens, Y. V. Ingelgem, et al., Investigation of the self-healing properties of shape memory polyurethane coatings with the 'odd random phase multisine' electrochemical impedance spectroscopy, Electrochim. Acta, 2010, 55(21), 6195-6203.

3 P. Zhang and G. Li, Advances in healing-on-demand polymers and polymer composites, Prog. Polym. Sci., 2016, 57, 32-63.

4 Y. Meng, G. Fang, J. Wang, et al., Photosensitizer-Loaded pHResponsive Hollow Gold Nanospheres for Single LightInduced Photothermal/Photodynamic Therapy, ACS Appl. Mater. Interfaces, 2015, 7(32), 17592.

5 M. Kopeć, K. Szczepanowicz, G. Mordarski, et al., Selfhealing epoxy coatings loaded with inhibitor-containing polyelectrolyte nanocapsules, Prog. Org. Coat., 2015, 84, 97106.

6 Z. Zheng, X. Huang, M. Schenderlein, et al., Bioinspired nanovalves with selective permeability and $\mathrm{pH}$ sensitivity, Nanoscale, 2015, 7(6), 2409-2416.

7 B. M. Bailey, Y. Leterrier, S. J. Garcia, et al., Electrically conductive self-healing polymer composite coatings, Prog. Org. Coat., 2015, 85, 189-198.

8 T. H. Tran, A. Vimalanandan, G. Genchev, et al., Regenerative nano-hybrid coating tailored for autonomous corrosion protection, Adv. Mater., 2015, 27(25), 3825.

9 W. Wang, T. Li and Z. Jin, Preparation of nanoiron/PMMA composite particles with core-shell structure through emulsion polymerization for nitrate removal, Abstracts of Papers, 234th ACS National Meeting, Boston, MA, United States, 19-23 August 2007, pp. 258-262.

10 L. Wang, L. Deng, D. Zhang, et al., Shape memory composite (SMC) self-healing coatings for corrosion protection, Prog. Org. Coat., 2016, 97, 261-268.

11 S. H. Boura, M. Peikari, A. Ashrafi, et al., Self-healing ability and adhesion strength of capsule embedded coatingsmicro and nano sized capsules containing linseed oil, Prog. Org. Coat., 2012, 75(4), 292-300.

12 T. Xie, Recent advances in polymer shape memory, Polymer, 2011, 52(22), 4985-5000.

13 Y. Wu, L. Wang, X. Zhao, et al., Self-healing supramolecular bioelastomers with shape memory property as a multifunctional platform for biomedical applications via modular assembly, Biomaterials, 2016, 104, 18.

14 M. Iannuzzi, J. Kovac and G. S. Frankel, A study of the mechanisms of corrosion inhibition of AA2024-T3 by vanadates using the split cell technique, Electrochim. Acta, 2007, 52(12), 4032-4042.

15 P. Kardar, Preparation of polyurethane microcapsules with different polyols component for encapsulation of isophorone diisocyanate healing agent, Prog. Org. Coat., 2015, 89, 271-276. 
16 Y. González-García, J. M. C. Mol, T. Muselle, et al., A combined mechanical, microscopic and local electrochemical evaluation of self-healing properties of shape-memory polyurethane coatings, Electrochim. Acta, 2011, 56(26), 9619-9626.

17 M. Xie, L. Wang, J. Ge, et al., Strong Electroactive Biodegradable Shape Memory Polymer Networks Based on Star-Shaped Polylactide and Aniline Trimer for Bone Tissue Engineering, ACS Appl. Mater. Interfaces, 2015, 7(12), 6772.

18 F. Lei, M. Hamdi, P. Liu, et al., Scratch behavior of epoxy coating containing self-assembled zirconium phosphate smectic layers, Polymer, 2017, 112, 252-263.

19 Y. Zhu, J. Shi, W. Shen, et al., Stimuli-responsive controlled drug release from a hollow mesoporous silica sphere/ polyelectrolyte multilayer core-shell structure, Angew. Chem., Int. Ed. Engl., 2005, 44(32), 5083-5087.

$20 \mathrm{~J}$. Zhou, H. Li, W. Liu, et al., A facile method to fabricate polyurethane based graphene foams/epoxy/carbon nanotubes composite for electro-active shape memory application, Composites, Part A, 2016, 91, 292-300.

21 L. Wang, X. Yang, H. Chen, et al., Design of triple-shape memory polyurethane with photo-cross-linking of cinnamon groups, ACS Appl. Mater. Interfaces, 2013, 5(21), 10520.

$22 \mathrm{X} . \mathrm{Zuo}, \mathrm{W} . \mathrm{Li}, \mathrm{S} . \mathrm{Mu}$, et al., Investigation of composition and structure for a novel Ti-Zr chemical conversion coating on 6063 aluminum alloy, Prog. Org. Coat., 2015, 87, 61-68.

23 M. Iannuzzi, J. Kovac and G. S. Frankel, A study of the mechanisms of corrosion inhibition of AA2024-T3 by vanadates using the split cell technique, Electrochim. Acta, 2007, 52(12), 4032-4042.

24 A. Baldan, Adhesively-bonded joints and repairs in metallic alloys, polymers and composite materials: adhesives, adhesion theories and surface pretreatment, J. Mater. Sci., 2004, 39(1), 1-49.

25 J. H. Nordlien, J. C. Walmsley, H. Østerberg, et al., Formation of a zirconium-titanium based conversion layer on AA 6060 aluminium, Surf. Coat. Technol., 2002, 153(1), 72-78.

26 O. Lunder, C. Simensen, Y. Yu, et al., Formation and characterisation of $\mathrm{Ti}-\mathrm{Zr}$ based conversion layers on
AA6060 aluminium, Surf. Coat. Technol., 2004, 184(2-3), 278-290.

27 K. Zhang, L. Wang and G. Liu, Copper(II) 8hydroxyquinolinate 3D network film with corrosion inhibitor embedded for self-healing corrosion protection, Corros. Sci., 2013, 75(7), 38-46.

28 I. A. Kartsonakis, A. C. Balaskas, E. P. Koumoulos, et al., Evaluation of corrosion resistance of magnesium alloy ZK10 coated with hybrid organic-inorganic film including containers, Corros. Sci., 2012, 65(12), 481-493.

29 W. Trabelsi, E. Triki, L. Dhouibi, et al., The use of pretreatments based on doped silane solutions for improved corrosion resistance of galvanised steel substrates, Surf. Coat. Technol., 2006, 200(14-15), 4240-4250.

30 K. Aramaki, Preparation of chromate-free, self-healing polymer films containing sodium silicate on zinc pretreated in a cerium(III) nitrate solution for preventing zinc corrosion at scratches in $0.5 \mathrm{M} \mathrm{NaCl}$, Corros. Sci., 2002, 44(6), 1375-1389.

31 C. Zhong, X. Tang and Y. F. Cheng, Corrosion of steel under the defected coating studied by localized electrochemical impedance spectroscopy, Electrochim. Acta, 2008, 53(14), 4740-4747.

32 S. Serajzadeh, S. R. Motlagh, S. M. H. Mirbagheri, et al., Deformation behavior of AA2017-SiCp in warm and hot deformation regions, Mater. Des., 2015, 67, 318-323.

33 S. Xiao, M. M. Hossain, P. Liu, et al., Scratch behavior of model polyurethane elastomers containing different soft segment types, Mater. Des., 2017, 132, 419-429.

34 G. Baranauskas, E. Maggiolini, E. Castagnola, et al., Carbon nanotube composite coating of neural microelectrodes preferentially improves the multiunit signal-to-noise ratio, J. Neural Eng., 2011, 8(6), 066013.

35 X. Yuan, Z. F. Yue, X. Chen, et al., Effect of mixture ratio on water uptake and corrosion performance of silicone-epoxy hybrid coatings coated 2024 Al-alloy, Prog. Org. Coat., 2015, 78, 168-175.

36 K. Pacaphol and D. Aht-Ong, The influences of silanes on interfacial adhesion and surface properties of nanocellulose film coating on glass and aluminum substrates, Surf. Coat. Technol., 2017, 320, 70-81. 